APPLIED HUMAN SCIENCE

Journal of Physiological Anthropology

\title{
Age-related Changes in Body Composition of 3- to 6-Year-old Japanese Children
}

\author{
Keisuke Teramoto, Kodo Otoki and Shuichi Komiya \\ Graduate School of Human-Environment Studies, Kyushu University
}

\begin{abstract}
This study was undertaken to establish an approach for the investigation of age-related changes in indices of body composition during childhood in Japan. It provides current reference values for total body fat mass (TBFM) and lean body mass (LBM) as indices of body composition in an urban population of 3- to 6year-old Japanese children. Moreover, we assessed the age-specific patterns of body fat distribution [subcutaneous fat mass (SFM) and internal fat mass (IFM)] during childhood. Measurements of body composition by bioelectrical impedance were made in 141 boys and 139 girls, all apparently healthy, aged 36 years. Determinations of impedance were made using a four-terminal impedance analyzer (TP-95K; Toyo Physical, Inc., Fukuoka, Japan). LBM was calculated using the equation of Kushner et al. (1992) and Goran et al. (1993). SFM was calculated using a modification of the equation derived by Skerjl et al. (1953). IFM was calculated as the difference between TBFM and SFM. From ages 3 through 6 years, the mean LBM increased with age in boys and girls, and showed significant age differences. Between the ages of 3 and 6 , the average increment in LBM was $5.1 \mathrm{~kg}$ in boys and $4.4 \mathrm{~kg}$ in girls. On average, boys gained $0.5 \mathrm{~kg}$ of TBFM each year, whereas girls gained $0.4 \mathrm{~kg}$ of TBFM each year. Furthermore, both groups gained $0.3 \mathrm{~kg}$ of SFM each year. Percentage body fat decreased in both genders until approximately the age of 5 , and increased again slightly at the age of 6 . The age-specific pattern of fat accumulation during childhood was characterized by an almost linear increase in SFM in girls, but a transient decrease in IFM in boys. We conclude that further research is required, including longitudinal assessment of body composition variables, in order to unravel the dynamics of body composition change in Japanese children.
\end{abstract}

$$
\text { (Appl Human Sci, } 18 \text { (5): 153-160, 1999) }
$$

Keywords: lean body mass, total body fat mass, subcutaneous fat mass, internal fat mass, children, bioelectrical impedance

\section{Introduction}

The fetus does not acquire appreciable amounts of body fat until the last trimester of gestation, although at birth the human neonate has a larger percentage of body fat than neonates of other mammals. Relative body fat continues to increase to a maximum value during the first 6 months of postnatal life, then falls to a nadir of about 13\% in boys and 16\% in girls in late childhood (Forbes, 1994). A number of studies have reported that rankings of fatness show stability between early infancy and childhood (Rolland-Cachera et al., 1987; Agras et al., 1990; Wells et al., 1996). Before puberty, boys and girls have similar average heights, body weights and body mass indices (Siervogel et al., 1991). However, recent studies using detailed body composition analysis in children found differences in fat mass between prepubertal boys and girls. Using dual-energy X-ray absorptiometry (DEXA) or bioelectrical impedance analysis (BIA) in healthy Dutch children and adolescents (aged 4-20 years), percentage body fat (\% fat) was higher in girls than in boys at all ages (Boot et al., 1997). In another study on children aged 38 years, DEXA measurements gave strong evidence for gender differences in fat mass: the \%fat was $13.5 \%$ and $20.4 \%$ in boys and girls, respectively (Taylor et al., 1997), and fat mass was significantly increased in girls aged 5-10 years when compared with boys (Nagy et al., 1997). It is of interest that sexual dimorphism in body composition is present in early life, well in advance of mature gonadal function.

A detailed description of the body composition of a 9year-old reference boy has been presented (Haschke et al., 1981). The major differences between the composition of the fat-free body mass of the 9 -year-old reference boy and that of the reference adult are as follows: there is a greater concentration of water and a lower concentration of minerals in the fat-free body mass of the 9-year-old reference boy, and concentrations of potassium and protein are slightly lower in the fat-free body mass of the 9-yearold than in that of the adult.

There is increasing evidence that the maintenance of 
a desirable body composition has important health implications. Childhood obesity is the leading cause of pediatric hypertension, and overweight children are at a higher risk for the development of a number of chronic conditions including adult onset diabetes mellitus, coronary heart disease, orthopedic disorders, and respiratory disease (Dietz, 1981). Excessive body weight in childhood has been linked to increasing risk for adult mortality (Nieto et al., 1992). Little is known, however, about the patterns of change in body composition in Japanese children and how these patterns of change relate to body composition later in life. Therefore, the primary objective of this study was to use bioelectrical impedance to determine whether there is an age difference in body composition.

The present study was undertaken to establish an approach for the investigation of age-related changes in indices of body composition in Japanese children.

\section{Subjects and Methods}

Measurements of body composition by bioelectrical impedance were made in 141 boys and 139 girls, all apparently healthy, aged 3-6 years. Our study population was homogenous with respect to BMI (that is, only BMI 1321 were studied). All subjects were of Japanese origin and lived in or within a $10 \mathrm{~km}$ radius of Fukuoka city. Measurements were obtained between October and November 1998 in 3 kindergartens.

Determinations of impedance were made using a fourterminal impedance analyzer (TP-95K; Toyo Physical, Inc., Fukuoka, Japan). Each subject wore clothes, but no shoes or socks, and was supine on a bed with limbs extended away from the trunk. After cleaning all skin contact areas with alcohol, current electrodes were placed on the dorsal surfaces of the right hand and foot at the distal metacarpals and metatarsals, respectively, and detector electrodes were applied at the right pisiform prominences of the wrist and between the medial and lateral malleoli at the ankle. This bioelectrical impedance analyzer generated an excitation current of $500 \mathrm{~mA}$ at a signal frequency of $50 \mathrm{kHz}$. The lean body mass (LBM) was calculated by the method of Goran et al. (1993) using the equation of Kushner et al. (1992):

$$
\begin{aligned}
\mathrm{LBM}(\mathrm{kg})= & \left(\mathrm{ht}^{2} / \text { resistance }\right) 0.59+(\mathrm{wt} \cdot 0.065)+ \\
& 0.04 / 0.769+(0.0025 \cdot \text { age })-(0.019 \cdot \\
& \text { gender })(1)
\end{aligned}
$$

where LBM is lean body mass; height (ht) is measured in centimeters, resistance (impedance index) in ohms, weight (wt) in kilograms, and age in years; and gender is 0 for girls and 1 for boys. Total body fat mass (TBFM) could then be calculated. Subcutaneous fat mass (SFM) was calculated using a modification (equation 2) of the equation derived by Skerjl et al. (1953):
SFM $(\mathrm{g})=[$ mean thickness of adipose tissue over body surface $(\mathrm{cm}) / 2 \cdot$ body surface area $\left(\mathrm{cm}^{2}\right) \cdot$ density of fat $\left.\left(\mathrm{g} / \mathrm{cm}^{3}\right)\right]-$ skin weight $(\mathrm{g})$

The mean thickness of adipose tissue was estimated by measuring the thickness of adipose tissue at 14 body sites (those used by Komiya et al., 1992), using a Harpenden skinfold caliper, and taking the mean value of these measurements. Body surface area was calculated using the equation of Fujimoto et al. (1968). The density of fat was taken as $0.900 \mathrm{~g} / \mathrm{cm}^{3}$ (Fidanza et al., 1953). Skin weight was calculated from body weight using the Satake and Ozaki equation (Satake and Ozaki, 1991). Internal fat mass (IFM) was calculated as the difference between TBFM and SFM.

Body weight was measured to the nearest $0.02 \mathrm{~kg}$ on a calibrated balance-beam scale with subjects wearing light underwear, and height was measured to the nearest $0.1 \mathrm{~cm}$. The body mass index (BMI; $\mathrm{kg} / \mathrm{m}^{2}$ ) was calculated from the formula body weight / height ${ }^{2}$. Somatotype was assessed by the Heath-Carter method (Carter, 1975).

Results are presented as means - standard deviation (S.D.). The significance of age differences was determined by Student's $t$ test for unpaired data after analysis of variance. Differences with $p$ values less than 0.05 were considered significant.

\section{Results}

The means and standard deviations of some physical characteristics of the subjects are shown in Table 1. From ages 3 to 6 years, the mean height and body weight increased with age in boys and girls, and showed significant age differences. In boys, the BMI progressively increased with age, but the differences were not statistically significant. In contrast, BMI decreased in girls until the age of 5 years, and increased again slightly at the age of 6 years. The mesomorphy points (second component) consistently decreased with age, although the ectomorphy points (third component) progressively increased with age in boys and girls.

Table 2 shows the mean skinfold measurements. There were few significant differences between the age groups in each skinfold measurement, although the 6-yearold girls' thigh, knee and suprailiac measurements, and the 6 -year-old boys' thigh measurement, were significantly larger than those of the 5-year-olds.

Body composition estimates for the subjects in each age group are outlined in Table 3. From ages 3 through 6 years, the mean LBM increased with age in boys and girls, and showed significant age differences. There were few significant differences between the age groups in each body fat variable, although TBFM and SFM in 6-year-old girls were significantly larger than those of 5-year-old girls. 
Table 1 Physical characteristics of children

\begin{tabular}{|c|c|c|c|c|c|c|c|c|}
\hline & \multicolumn{2}{|c|}{ 3yr-Group } & \multicolumn{2}{|c|}{ 4yr-Group } & \multicolumn{2}{|c|}{ 5yr-Group } & \multirow{2}{*}{$\begin{array}{c}\text { 6yr-Group } \\
\text { Mean - S.D. }\end{array}$} & \multirow{2}{*}{$\begin{array}{c}\text { Total } \\
\text { Mean - S.D. }\end{array}$} \\
\hline & Mean - S.D. & $\begin{array}{c}\text { Age } \\
\text { Difference }\end{array}$ & Mean - S.D. & $\begin{array}{c}\text { Age } \\
\text { Difference }\end{array}$ & Mean - S.D. & $\begin{array}{c}\text { Age } \\
\text { Difference }\end{array}$ & & \\
\hline Age, yr & $3.7-0.2$ & $* * *$ & $4.4-0.3$ & $* * *$ & $5.5-0.3$ & $* * *$ & $6.3-0.1$ & $5.0-0.9$ \\
\hline Height, cm & $97.7-2.9$ & $* * *$ & $102.3-4.3$ & $* * *$ & $108.6-5.0$ & $* * *$ & $114.5-4.9$ & $106.0-7.1$ \\
\hline Body Weight, kg & $14.74-1.33$ & $* *$ & $16.33-2.22$ & $* * *$ & $18.36-2.51$ & $* * *$ & $20.88-2.87$ & $17.65-3.07$ \\
\hline Second Component & $5.01-0.61$ & & $4.86-0.50$ & $* * *$ & $4.42-0.75$ & & $4.34-0.53$ & $4.65-0.65$ \\
\hline Third Component & $0.89-0.60$ & & $1.15-0.57$ & $* * *$ & $1.69-0.86$ & & $1.98-0.83$ & $1.45-0.81$ \\
\hline Girls & $\mathrm{n}=19$ & & $n=55$ & & $\mathrm{n}=37$ & & $\mathrm{n}=28$ & $\mathrm{n}=139$ \\
\hline Age, yr & $3.7-0.2$ & $* * *$ & $4.5-0.3$ & $* * *$ & $5.5-0.3$ & $* * *$ & $6.2-0.1$ & $5.0-0.9$ \\
\hline Height, cm & $97.4-4.4$ & $* * *$ & $102.5-4.2$ & $* * *$ & $107.9-3.8$ & $* * *$ & $113.7-3.6$ & $105.5-6.6$ \\
\hline Third Component & $0.72-0.49$ & $* *$ & $1.24-0.72$ & $* * *$ & $1.95-0.69$ & & $2.02-0.83$ & $1.51-0.85$ \\
\hline
\end{tabular}

First Component; (or endomorphy) refers to relative fatness in physiques, it also refers to relative leanness. Second Component; (or mesomorphy) refers to relative musculo-skeletal development per unit of height. Third Component; (or ectomophy) refers to relative linearity of individual physiques. $* \mathrm{p}<0.05, * * \mathrm{p}<0.01, * * * \mathrm{p}<0.001$.

Table 2 Skinfold characteristics of children

\begin{tabular}{|c|c|c|c|c|c|c|c|c|}
\hline & \multicolumn{2}{|c|}{ 3yr-Group } & \multicolumn{2}{|c|}{ 4yr-Group } & \multicolumn{2}{|c|}{ 5yr-Group } & \multirow{2}{*}{$\begin{array}{c}\text { 6yr-Group } \\
\text { Mean - S.D. }\end{array}$} & \multirow{2}{*}{$\begin{array}{c}\text { Total } \\
\text { Mean - S.D. }\end{array}$} \\
\hline & Mean - S.D. & $\begin{array}{c}\text { Age } \\
\text { Difference }\end{array}$ & Mean - S.D. & $\begin{array}{c}\text { Age } \\
\text { Difference }\end{array}$ & Mean - S.D. & $\begin{array}{c}\text { Age } \\
\text { Difference }\end{array}$ & & \\
\hline Boys & $\mathrm{n}=17$ & & $n=54$ & & $\mathrm{n}=42$ & & $n=28$ & $\mathrm{n}=141$ \\
\hline Chest I, mm & $6.2-1.6$ & & $6.2-2.0$ & & $6.9-2.7$ & & $7.0-3.6$ & $6.6-2.5$ \\
\hline Chest II, mm & $4.8-1.1$ & & $5.0-1.5$ & & $4.7-1.6$ & & $5.3-2.1$ & $4.9-1.6$ \\
\hline Suprailiac, mm & $5.7-1.4$ & & $6.4-3.0$ & & $6.3-3.7$ & & $7.2-4.8$ & $6.4-3.5$ \\
\hline Abdomen, mm & $6.9-1.3$ & & $6.8-2.7$ & & $6.8-3.3$ & & $7.5-4.2$ & $7.0-3.1$ \\
\hline Triceps, mm & $10.7-2.7$ & & $10.9-2.0$ & & $10.5-2.8$ & & $10.6-3.0$ & $10.7-2.5$ \\
\hline Scapula, mm & $6.4-1.4$ & & $6.4-2.1$ & & $6.5-2.3$ & & $7.2-3.4$ & $6.6-2.4$ \\
\hline Thigh, mm & $11.6-2.8$ & & $12.3-4.0$ & & $12.0-3.6$ & $*$ & $14.3-4.7$ & $12.5-4.0$ \\
\hline Knee, mm & $10.6-2.7$ & & $9.2-2.7$ & $* * *$ & $7.6-2.1$ & & $8.7-2.9$ & $8.8-2.7$ \\
\hline Girls & $\mathrm{n}=19$ & & $n=55$ & & $\mathrm{n}=37$ & & $\mathrm{n}=28$ & $\mathrm{n}=139$ \\
\hline Chest I, mm & $6.4-1.7$ & & $6.9-3.0$ & & $7.3-2.4$ & & $7.7-2.5$ & $7.1-2.6$ \\
\hline Chest II, mm & $4.9-0.9$ & & $5.3-1.7$ & & $5.2-1.6$ & & $6.1-1.1$ & $5.4-1.7$ \\
\hline Suprailiac, mm & $7.8-2.6$ & & $7.8-3.0$ & & $7.7-3.3$ & $*$ & $9.5-3.6$ & $8.1-3.2$ \\
\hline Abdomen, mm & $7.9-1.5$ & & $7.7-2.2$ & & $7.4-2.8$ & & $8.9-3.8$ & $7.9-2.7$ \\
\hline Triceps, mm & $12.1-1.7$ & & $11.3-2.0$ & & $10.6-2.4$ & & $11.9-2.8$ & $11.4-2.3$ \\
\hline Scapula, mm & $7.0-1.9$ & & $7.0-2.6$ & & $7.1-2.4$ & & $8.0-3.1$ & $7.2-2.6$ \\
\hline Thigh, mm & $14.4-2.4$ & & $14.1-3.2$ & & $13.1-2.7$ & $* *$ & $15.8-3.7$ & $14.2-3.2$ \\
\hline Knee, mm & $11.1-2.5$ & & $10.1-2.9$ & $* * *$ & $7.1-2.1$ & $* * *$ & $10.4-4.6$ & $9.5-3.4$ \\
\hline
\end{tabular}

Chest I; diagonal fold just superior and lateral to the nipple, Chest II; vertical fold on the midaxillary line at the level of the xiphoid process. Thigh; vertical fold on the anterior aspect of the thigh midway between the superior aspect of the patella and anterior superior iliac spine. $* \mathrm{p}<0.05, * * \mathrm{p}<0.01, * * * \mathrm{p}<0.001$.

Fig. 1 shows the calculated regression lines for LBM as a function of age for boys and girls. The correlation coefficient between LBM and age was 0.697 for boys and 0.701 for girls. These correlation coefficients were significant. There was no significant gender difference between the means of LBM for boys or girls. On average, boys gained $1.9 \mathrm{~kg}$ of LBM each year, whereas girls gained $1.7 \mathrm{~kg}$. 
Table 3 Body composition characteristics of children

\begin{tabular}{|c|c|c|c|c|c|c|c|c|}
\hline & \multicolumn{2}{|c|}{ 3yr-Group } & \multicolumn{2}{|c|}{ 4yr-Group } & \multicolumn{2}{|c|}{ 5yr-Group } & \multirow{2}{*}{$\begin{array}{c}\text { 6yr-Group } \\
\text { Mean - S.D. }\end{array}$} & \multirow{2}{*}{$\begin{array}{c}\text { Total } \\
\text { Mean - S.D. }\end{array}$} \\
\hline & Mean - S.D. & $\begin{array}{c}\text { Age } \\
\text { Difference }\end{array}$ & Mean - S.D. & $\begin{array}{c}\text { Age } \\
\text { Difference }\end{array}$ & Mean - S.D. & $\begin{array}{c}\text { Age } \\
\text { Difference }\end{array}$ & & \\
\hline Boys & $\mathrm{n}=17$ & & $\mathrm{n}=54$ & & $\mathrm{n}=42$ & & $\mathrm{n}=28$ & $\mathrm{n}=141$ \\
\hline LBM, kg & $11.9-1.0$ & $* * *$ & $13.5-1.8$ & $* * *$ & $15.2-1.8$ & $* * *$ & $17.0-2.2$ & $14.5-2.4$ \\
\hline TBFM, kg & $2.9-0.7$ & & $2.8-1.0$ & & $3.2-1.6$ & & $3.9-1.6$ & $3.1-1.3$ \\
\hline $\mathrm{SFM}, \mathrm{kg}$ & $1.6-0.4$ & & $1.2-0.8$ & & $1.3-0.9$ & & $1.8-1.2$ & $1.3-0.9$ \\
\hline IFM, kg & $1.8-0.5$ & & $1.6-0.7$ & & $1.8-1.0$ & & $2.1-0.9$ & $1.8-0.8$ \\
\hline LBM/Weight, \% & $80.7-3.6$ & & $83.0-4.6$ & & $83.2-5.8$ & & $81.6-5.8$ & $82.5-5.2$ \\
\hline TBFM/Weight, \% & $19.3-3.6$ & & $17.0-4.6$ & & $16.8-5.8$ & & $18.4-5.8$ & $17.5-5.2$ \\
\hline $\mathrm{SFM} / \mathrm{TBFM}$ & $0.36-0.10$ & & $0.44-0.17$ & & $0.43-0.18$ & & $0.44-0.19$ & $0.43-0.17$ \\
\hline IFM/TBFM & $0.64-0.10$ & & $0.56-0.17$ & & $0.57-0.18$ & & $0.56-0.19$ & $0.57-0.17$ \\
\hline LBM/TBFM & $4.37-1.01$ & $*$ & $5.32-1.70$ & & $5.51-1.87$ & & $4.90-1.70$ & $5.18-1.71$ \\
\hline Girls & $\mathrm{n}=19$ & & $\mathrm{n}=55$ & & $n=37$ & & $\mathrm{n}=28$ & $\mathrm{n}=139$ \\
\hline LBM, kg & $11.8-1.3$ & $* * *$ & $13.1-1.2$ & $* * *$ & $14.2-1.7$ & $* * *$ & $16.2-2.0$ & $13.8-2.1$ \\
\hline TBFM, kg & $3.2-0.7$ & & $3.1-1.0$ & & $3.2-1.2$ & $* *$ & $4.2-1.5$ & $3.4-1.2$ \\
\hline $\mathrm{SFM}, \mathrm{kg}$ & $1.3-0.4$ & & $1.4-0.6$ & & $1.4-0.7$ & $* * *$ & $2.1-1.0$ & $1.5-0.7$ \\
\hline IFM, kg & $1.9-0.6$ & & $1.7-0.7$ & & $1.8-0.8$ & & $2.1-1.0$ & $1.8-0.8$ \\
\hline LBM/Weight, \% & $78.9-3.9$ & & $80.9-5.3$ & & $81.6-5.6$ & & $79.6-5.9$ & $80.6-5.4$ \\
\hline TBFM/Weight, \% & $21.1-3.9$ & & $19.1-5.3$ & & $18.4-5.6$ & & $20.4-5.9$ & $19.4-5.4$ \\
\hline SFM/TBFM & $0.42-0.11$ & & $0.46-0.13$ & & $0.43-0.14$ & & $0.50-0.15$ & $0.46-0.14$ \\
\hline IFM/TBFM & $0.58-0.11$ & & $0.54-0.13$ & & $0.57-0.14$ & & $0.50-0.15$ & $0.55-0.14$ \\
\hline LBM/TBFM & $3.90-0.99$ & & $4.63-1.56$ & & $4.95-1.84$ & & $4.33-1.58$ & $4.56-1.60$ \\
\hline
\end{tabular}

LBM; lean body mass, TBFM; total body fat mass, SFM; subcutaneous fat mass, IFM; internal fat mass, Weight; body weight. $* \mathrm{p}<0.05, * * \mathrm{p}<0.01, * * * \mathrm{p}<0.001$.

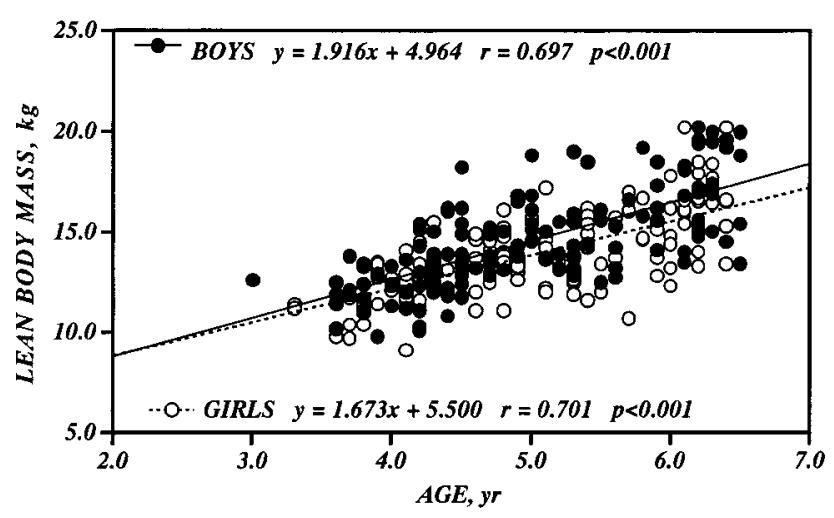

Fig. 1 Relationship between lean body mass and age

Fig. 2 shows the relationship between LBM or TBFM and height. The correlation coefficients of LBM and TBFM with height were $0.880(p<0.001)$ and $0.389(p<0.001)$, respectively, for boys, and $0.869(\mathrm{p}<0.001)$ and 0.290 $(p<0.01)$, respectively, for girls. The regression slope for TBFM versus height was significantly influenced by gender, with a significantly lower regression slope in girls than in boys $(p<0.01)$. On average the regression slope was about $0.3 \mathrm{~kg}$ of LBM/cm and about $0.07 \mathrm{~kg}$ of TBFM/cm in boys, and about $0.3 \mathrm{~kg}$ of $\mathrm{LBM} / \mathrm{cm}$ and about $0.05 \mathrm{~kg}$ of TBFM/ $\mathrm{cm}$ in girls.
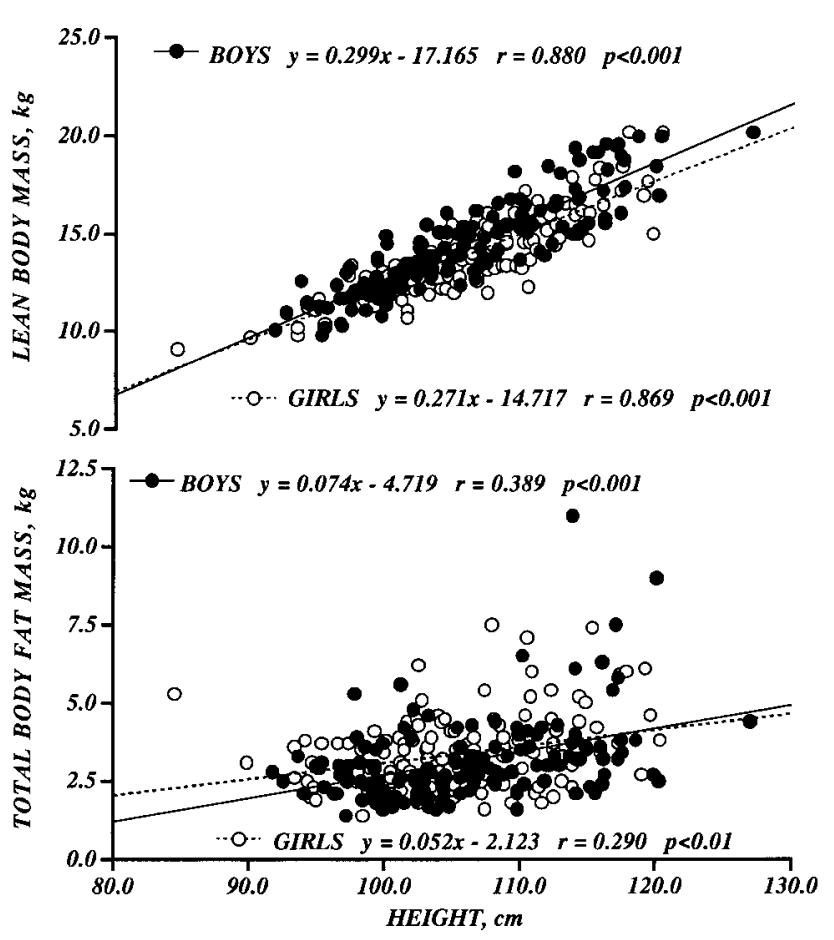

Fig. 2 Lean body mass and total body fat mass as a function of height 

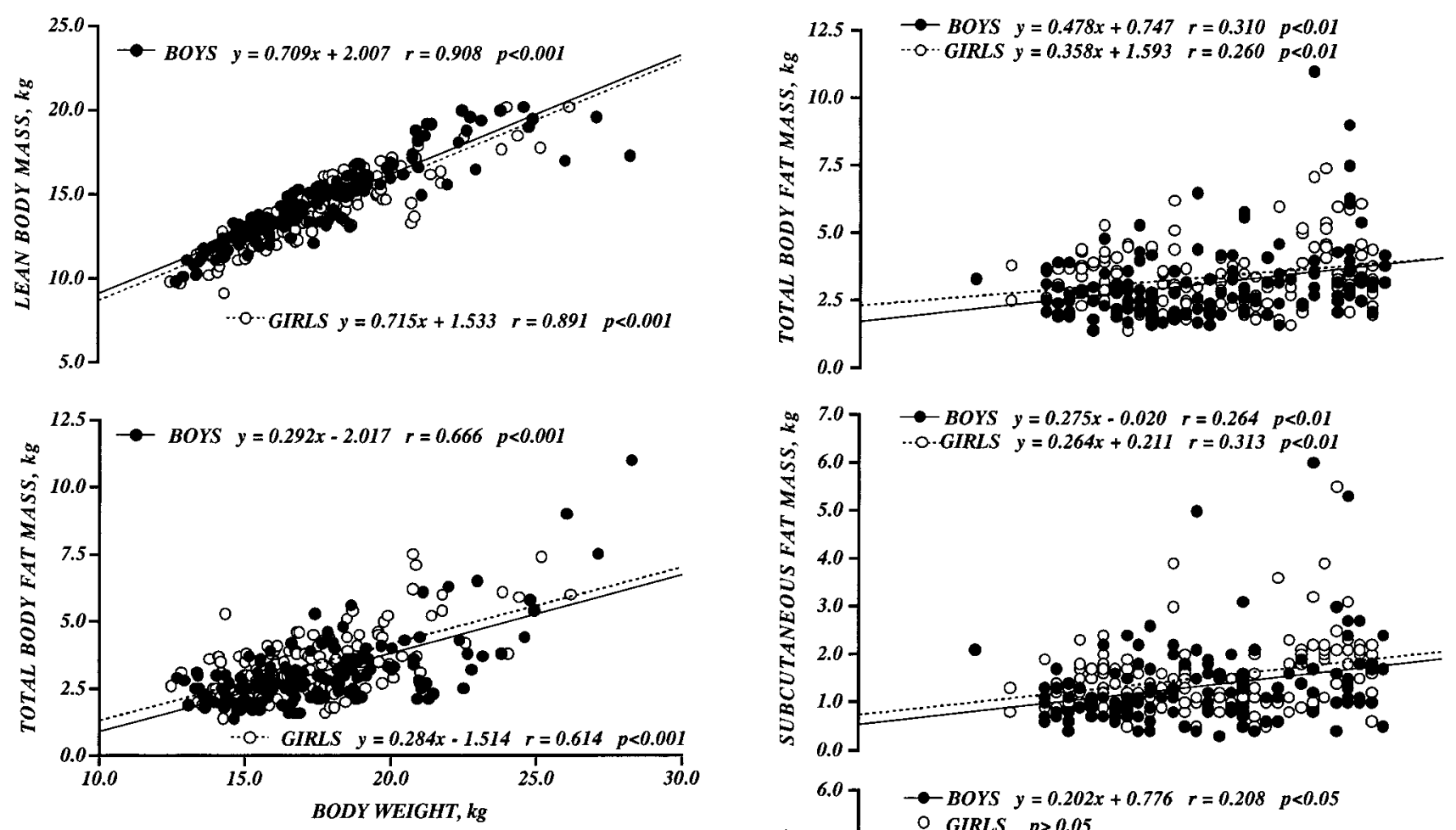

Fig. 3 Lean body mass and total body fat mass as a function of body weight

Fig. 3 shows the relationship between LBM or TBFM and body weight. The correlation coefficients of LBM and TBFM with body weight were 0.908 and 0.666 , respectively, for boys, and 0.891 and 0.614 , respectively, for girls. All the correlation coefficients were significant $(p<0.001)$. On average the regression slope was about $0.7 \mathrm{~kg}$ of $\mathrm{LBM} / \mathrm{kg}$ and about $0.3 \mathrm{~kg}$ of TBFM $/ \mathrm{kg}$ in boys and girls.

Fig. 4 shows the calculated regression lines for TBFM, SFM and IFM as a function of age for boys and girls. The correlation coefficients between TBFM, SFM or IFM and age were $0.310(p<0.01), 0.264(p<0.01)$ and $0.208(p<0.05)$, respectively, for boys. The correlation coefficients between TBFM or SFM and age were $0.260(\mathrm{p}<0.01)$ and 0.313 $(p<0.01)$, respectively, for girls. However, the correlation coefficient between IFM and age was not significant in girls $(r=0.099)$. The regression slope for TBFM versus age was significantly influenced by gender, with a significantly lower regression slope in girls than in boys $(p<0.05)$. On average, boys gained $0.5 \mathrm{~kg}$ of TBFM each year, whereas girls gained $0.4 \mathrm{~kg}$ of TBFM each year. Furthermore, both groups gained $0.3 \mathrm{~kg}$ of SFM each year.

Fig. 5 shows the relationship between SFM or IFM and TBFM. All the correlation coefficients were significant $(p<0.001)$. There were no significant gender differences between the correlation coefficients of these regression lines. On the other hand, the relationship between SFM and IFM was extremely weak and statistically non-significant in

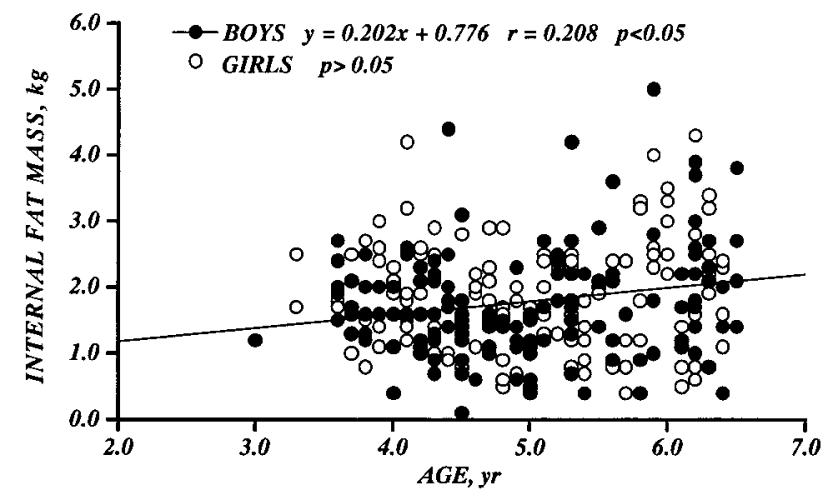

Fig. 4 Relationship between total body fat mass, subcutaneous fat mass and internal fat mass and age

both genders (for boys, $r=0.001$; for girls, $r=0.139$ ).

Body composition characteristics in children are summarized in Fig. 6. The 3-year-old boys had more IFM than the 4-year-old boys; expressed as a percentage of body weight, IFM estimated by the two-component model was significantly higher in the 3 -year-old boys $(12.2 \%$ vs $9.8 \% ; \mathrm{p}<0.05)$. However, the SFM did not differ significantly between the two groups. The SFM as a percentage of body weight averaged approximately $7.3 \%$ for each group of boys. The 6-year-old girls had more SFM than the 5-year-old girls; the SFM as a percentage of body weight was significantly higher in the 6-year-old girls $(10.0 \%$ vs $7.8 \% ; \mathrm{p}<0.01)$. However, the IFM as a percentage of body weight averaged $10.8 \%$ for each group of girls. The age differences in the LBM as a percentage of body weight were not significant in either gender. 

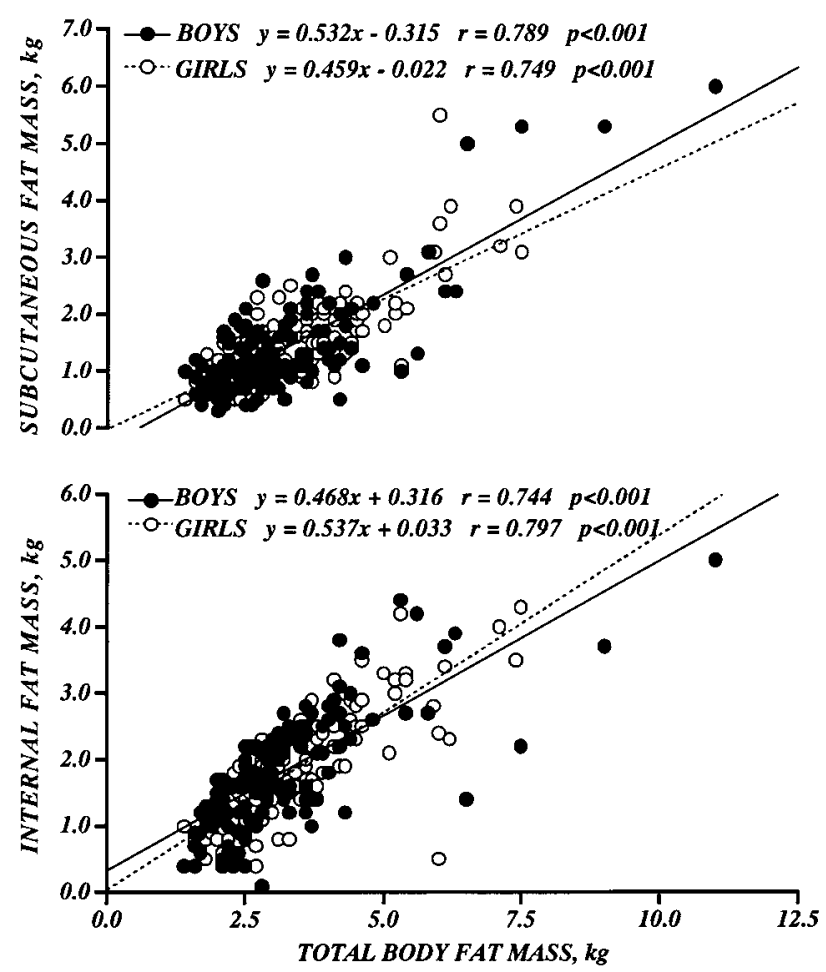

Fig. 5 Subcutaneous and internal fat mass as a function of total body fat mass

\section{Discussion}

This study provides current reference values for TBFM and LBM as indices of body composition in an urban population of 3- to 6-year-old Japanese children. Moreover, we assessed the age-specific patterns of body fat distribution (SFM and IFM) during childhood.

A well-known and widely applied model for studying body composition in humans is the two-component model (Lukaski, 1987). This model divides the human body into two components, one consisting of TBFM and one consisting of LBM. The basis of the two-component model stems from the results of analyses of cadavers. These analyses show that the human body consists of a TBFM and a LBM (bones, muscles, water and organs) of a relatively constant composition. The chemical and physical properties, especially the density and water content, of the TBFM and LBM can be measured or calculated with reasonable precision. However, a major drawback of these procedures is that it is not known whether in an individual case or a specific group of persons the derived constants for the density or water content of the LBM are valid.

Densitometry has drawbacks, and its validity for assessing body composition is doubtful when applied to children (Lohman et al., 1984). In addition, it should be noted that densitometry is a time-consuming method requiring considerable equipment that is usually only available in specialized laboratories. This means that densitometry is not a suitable technique for the routine assessment of body composition in large groups of children.

Skinfold thickness measurements provide an estimate of the amount of subcutaneous fat, which correlates well with TBFM as assessed from densitometry. This provides the rationale for calculating body fat percentage from a regression equation of skinfold thicknesses on total body density. Several regression equations have been published (Nagamine and Suzuki, 1964; Sloan, 1967; Durnin and Womersley, 1974; Lohman, 1981). For children, a few regression equations exist to relate skinfold thickness to
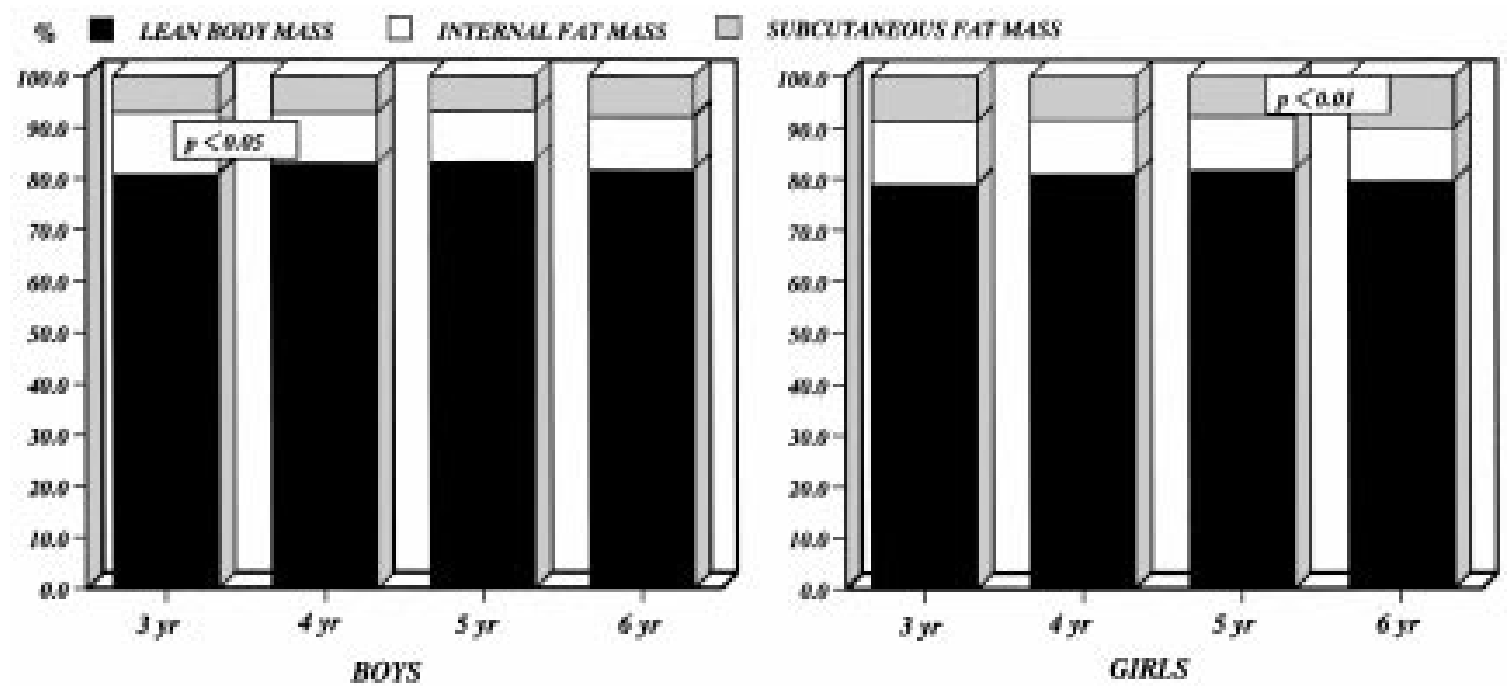

Fig. 6 Changes in body composition as a percentage of body weight with age 
total body fat percentage (Forbes and Amirhakimi, 1970; Lohman et al., 1975). However, predictive equations relating a subject's skinfold thickness to measured total body density (by underwater weighing) have not been developed for use in Japanese children aged $<8$ years. The reasons are twofold: first, it is difficult for practical reasons to obtain total body density measurements in children, and secondly an important assumption of the two-component model regarding the density of LBM is probably only valid for adults and not for children. Therefore, there have been no studies of changes with age in the body composition of Japanese children.

In the present study, body composition was calculated by BIA using the equation of Kushner et al. (1992) and Goran et al. (1993). BIA is an appealing tool for in vivo assessment of body composition because it is simple, quick, and inexpensive to perform. The technique of BIA is of particular appeal for use in children because other available body composition methods either require complicated test procedures that are impractical for young children to perform (e.g., underwater weighing) or involve radiation exposure (e.g., neutron activation). The use of BIA in children has been examined specifically at several laboratories. Kushner et al. (1992) used data from neonates, preschool children, prepubertal children, and adults to derive one universal equation for estimating total body water from height ${ }^{2} /$ resistance that was applicable across a wide age range, although the authors remained uncertain of the accuracy of the equation in preschool children. However, after this study, Goran et al. (1993) concluded that the relationship between total body water (by $\mathrm{H}_{2}{ }^{18} \mathrm{O}$ dilution) and height ${ }^{2} /$ resistance in 4 - to 6-yearold children has been verified across independent laboratories and that the Kushner equation relating these two variables is valid in young children.

It is generally accepted that children are not chemically mature at 2 or 3 years after birth. Before puberty, boys and girls have similar average height, body weight and BMI (Siervogel et al., 1991). Age-related changes in fat mass are generally considered to become manifest after puberty. However, there are very few data on body composition in Japanese children. In addition, there have been no studies of age-related changes in body fat distribution (i.e. the relative proportions of SFM and IFM), a parameter that varies with ethnicity and illness. Age-related change in body fat distribution is an important aspect of health related to nutritional status.

In the present study, a steady increase in LBM with age was observed in both genders. On average, boys gained $1.9 \mathrm{~kg}$ of LBM each year, whereas girls gained $1.7 \mathrm{~kg}$. Between the ages of 3 and 6 years the average increment in LBM was $5.1 \mathrm{~kg}$ in boys and $4.4 \mathrm{~kg}$ in girls. In boys aged 3 to 6 years, age-related changes in TBFM, SFM and IFM were not evident. On the other hand, the TBFM and SFM of 6-year-old girls were significantly larger than those of 5-year-old girls. The age-specific pattern of fat accumulation during childhood was characterized by an almost linear increase in SFM in girls, but a transient decrease in IFM in boys. Percentage body fat decreased in both genders until approximately the age of 5, and increased again slightly at the age of 6 .

Several studies have shown that although not all fat children are fat in later life, they have an increased risk of being so in comparison to children of normal weight (Zack et al., 1979). Earlier studies investigating the development of fatness in infancy and childhood tended to focus on the potential role of variation in early energy intake. However, such studies had limited success in explaining the development of fatness, and results appeared to be inconsistent. The new hypothesis is that rather than high energy intake leading to greater fatness, the cause is reduced energy expenditure on physical activity (Roberts et al., 1988). The increasing prevalence of inactive leisure pursuits, such as watching television and playing computer games, is of concern as evidence is emerging linking these activities directly to obesity. Change in eating styles is also an important contributing factor to the increasing level of overweight and obesity. An increasing prevalence of childhood obesity has been reported within the last two decades in Japan. Consequently, further research is required, including longitudinal assessment of body composition variables, in order to unravel the dynamics of body composition change in Japanese children.

\section{References}

Agras WS, Kraemer HC, Berkowitz RI, Hammer LD (1990) Influence of early feeding style on adiposity at 6 years of age. J Pediatr 116: 805-809

Boot AM, Bouquet J, de Ridder MAJ, Krenning EP, de Muinck Keizer-Schrama SMPF (1997) Determinants of body composition measured by dual energy X-ray absorptiometry in Dutch children and adolescents. Am J Clin Nutr 66: 232-238

Carter JEL (1975) The Heath-Carter somatotype method. San Diego State Univ, The Campanile Press, San Diego Dietz WH (1981) Obesity in infants, children, and adolescents in the United States. Identification, natural history, and aftereffects. Nutr Res 1: 117-137

Durnin JVGA, Womersley J (1974) Body fat assessed from body density and its estimation from skinfold thickness: measurement on 481 men and women from 12-72 years. Br J Nutr 32: 77-97

Fidanza F, Keys A, Anderson JT (1953) Density of body fat in man and other mammals. J Appl Physiol 6: 252256

Forbes GB, Amirhakimi GH (1970) Skinfold thickness and body fat in children. Hum Biol 42: 401-418

Forbes GB (1994) Body composition: Influence of nutrition, disease, growth, and aging. In Modern 
nutrition in health and disease. 8th ed. Edited by Shils ME, Olson JA, Shike M, Lea \& Febiger, Philadelphia Fujimoto S, Watanabe T, Sakamoto K, Yukawa K, Morimoto K (1968) Studies on the physical surface area of Japanese. Part 18, Calculation formulas in three stages over all ages. Jpn J Hyg 23: 443-450 (in Japanese)

Goran MI, Kaskoun MC, Carpenter WH, Poehlman ET, Ravussin E, Fontvieikke A-M (1993) Estimating body composition of young children by using bioelectrical resistance. J Appl Physiol 75: 1776-1780

Haschke F, Fomon SJ, Ziegler EE (1981) Body composition of a nine-year-old reference boy. Pediatr Res 15: 847-849

Komiya S, Muraoka Y, Zhang F-S, Masuda T (1992) Agerelated changes in body fat distribution in middle-aged and elderly Japanese. J Anthrop Soc Nippon 100: 161169

Kushner RF, Schoeller DA, Fjeld CR, Danford L (1992) Is the impedance index (ht/2/R) significant in predicting total body water? Am J Clin Nutr 56: 835-839

Lohman TG, Boileau RA, Massey BH (1975) Prediction of lean body mass in young boys from skinfold thickness and body weight. Hum Biol 47: 245-262

Lohman TG (1981) Skinfolds and body density and their relation to body fatness: a review. Hum Biol 53: 181225

Lohman TG, Slaughter MH, Boileau RA, Bunt J, Lussier $\mathrm{L}$ (1984) Bone mineral measurements and their relation to body density in children, youth and adults. Hum Biol 56: 667-679

Lukaski HC (1987) Methods for the assessment of human body composition: traditional and new. Am J Clin Nutr 46: $537-556$

Nagamine S, Suzuki S (1964) Anthropometry and body composition of Japanese young men and women. Hum Biol 36: 8-15

Nagy TR, Gower BA, Trownbridge CA, Dezenberg C, Shewchuk M, Goran M (1997) Effects of gender, ethnicity, body composition, and fat distribution on serum leptin concentrations in children. J Clin Endo Metab 82: 2148-2152
Nieto FJ, Szklo M, Comstock GW (1992) Childhood weight and growth rate as predictors of adult mortality. Am J Epidemiol 136: 201-213.

Roberts SB, Savage J, Coward WA, Chew B, Lucas A (1988) Energy expenditure and intake in infants born to lean and overweight mothers. New Engl J Med 318: 461-466

Rolland-Cachera M, Deheeger M, Guilbud-Bataille M, Avons P, Patois E, Sempe M (1987) Tracking the development of adiposity from 1 month of age to adulthood. Ann Hum Biol 14: 219-229

Satake T, Ozaki T (1991) Skin and subcutaneous adipose tissue weights in older Japanese determined by cadaver dissection. Am J Hum Biol 9: 371-376

Siervogel RM, Roche AF, Guo S, Mukherjee D, Chumlea WC (1991) Patterns of change in weight/stature ${ }^{2}$ from 2 to 18 years: findings from long-term serial data for children in Fels longitudinal growth study. Int J Obes 15: 479-485

Skerjl B, Brozek J, Hunt EE (1953) Subcutaneous fat and age changes in body build and body form in women. Am J Phys Anthrop 11: 577-580

Sloan AW (1967) Estimation of body fat in young men. J Appl Physiol 23: 311-315

Taylor RW, Gold E, Manning P, Goulding A (1997) Gender differences in body fat content are present well before puberty. Int J Obes 21: 1082-1084

Wells JCK, Stanley M, Laidlaw AS, Day JE, Davies PSW (1996) The relationship between components of infant energy expenditure and childhood body fatness. Int J Obes 20: 848-853

Zack PM, Harlan WR, Leaveton PE, Cornoni-Huntley J (1979) A longitudinal study of body fatness in childhood and adolescence. J Pediatr 95: 126-130

Received: March 15, 1999

Accepted: June 11, 1999

Correspondence to: Keisuke Teramoto, Graduate School of Human-Environment Studies, Kyushu University, 61 Kasuga-kouen, Kasuga 816-8580, Japan e-mail: keisuke@ihs.kyushu-u.ac.jp 